\title{
Investigation on Solid-State Phase Transformations in a 2510 Duplex Stainless Steel Grade
}

\author{
Irene Calliari ${ }^{1}$, Marco Breda ${ }^{2}$, Claudio Gennari ${ }^{1, *} \mathbb{C}$, Luca Pezzato ${ }^{1}\left(\mathbb{D}\right.$, Massimo Pellizzari ${ }^{3}(\mathbb{D}$ \\ and Andrea Zambon 4 \\ 1 Department of Industrial Engineering, University of Padova, Via Marzolo, 9, 35131 Padova, Italy; \\ irene.calliari@unipd.it (I.C.); luca.pezzato@unipd.it (L.P.) \\ 2 Unilab Laboratori Industriali S.r.l., Via Umbria 22, 35043 Monselice (PD), Italy; marco.breda1981@gmail.com \\ 3 Department of Industrial Engineering, University of Trento, Via Sommarive 9, 38123 Trento, Italy; \\ massimo.pellizzari@unitn.it \\ 4 Department of Management and Engineering, University of Padua, Stradella S. Nicola 3, 36100 Vicenza, \\ Italy; a.zambon@unipd.it \\ * Correspondence: claudio.gennari@unipd.it or claudio.gennari1@gmail.com; Tel.: +39-049-8275498
}

Received: 12 June 2020; Accepted: 14 July 2020; Published: 17 July 2020

\begin{abstract}
Duplex and Super Duplex Stainless Steels are very prone to secondary phases formation related to ferrite decomposition at high temperatures. In the present paper the results on secondary phase precipitation in a 2510 Duplex Stainless Steel, heat-treated in the temperature range $850-1050{ }^{\circ} \mathrm{C}$ for 3-30 min are presented. The precipitation starts at grain boundaries with a consistent ferrite transformation for very short times. The noses of the Time-Temperature-Precipitation (TTP) curves are at $1000{ }^{\circ} \mathrm{C}$ for $\sigma$-phase and at $900{ }^{\circ} \mathrm{C}$ for $\chi$-phase, respectively. The precipitation sequence involves a partial transformation of $\chi$ into $\sigma$, as previously evidenced in 2205 and 2507 grades. Furthermore, the experimental data were compared to the results of Thermo-Calc calculations. Understanding and ability to predict phase stability in 2510 duplex stainless steel is a key factor to design optimal welding processes that avoid any secondary phase precipitation in the weld bead as well as in the heat-affected zone.
\end{abstract}

Keywords: duplex stainless steels; isothermal heat treatment; secondary phase precipitation; TTP curves

\section{Introduction}

Duplex Stainless Steels (DSSs) and Super Duplex Stainless Steels (SDSSs) possess high mechanical and corrosion resistance properties, which can be ascribed to the presence of the characteristic biphasic structure, where austenite and ferrite are present in almost equal volume fractions $[1,2]$. If the ferrite-to-austenite phase ratio is indeed in the range 0.4-0.6, these steels reach their most advantageous properties.

All DSSs solidify as fully ferritic, while austenite forms upon cooling as a consequence of a solid-state transformation, whose temperature is related to the chemical composition of the steel. The correct balance of alloying elements and proper design of the solution annealing treatment allow obtaining the required amount of each phase, which affects the microstructural stability.

The instability of phases pertains to the possibility and susceptibility to further solid-state transformations which result in the formation of harmful intermetallic phases, especially above $600{ }^{\circ} \mathrm{C}$, which restricts the use of the DSS in a limited temperature range [3-6]. Such solid-state phase transformations can occur during isothermal aging, welding or cooling after the solubilization treatment and are mainly concerned with ferrite decomposition, because alloying elements diffusivities 
are higher in ferrite than in austenite. Moreover, ferrite is enriched in chromium and molybdenum, which are known to enhance the formation of intermetallic phases.

The cooling rate has a considerable impact on the ferrite-to-austenite ratio at room temperature and on the precipitation of secondary phases, therefore, during cooling operations, special care must be taken in the temperature range between $1000^{\circ} \mathrm{C}$ and $600^{\circ} \mathrm{C}$, in order to avoid the precipitation of harmful secondary phases such as $\sigma$-phase, $\chi$-phase, carbides and nitrides [7]. Despite these technological aspects, a complete and definitive description of secondary phases formation in DSSs is still unavailable and several different precipitation sequences of various intermetallic phases have been proposed. Some authors $[3,4,8,9]$ suggest that the precipitation of $\sigma$-phase is associated with intermediate precipitation of $\chi$-phase, which subsequently transforms into $\sigma$-phase, while some other authors associate the phase formations to nitride precipitation [10]. Additionally, in lean duplex stainless steels, the precipitation of $\sigma$ was observed without any $\chi$-phase precipitation [11].

It has been verified that the critical formation time for $\sigma$ or other phases depends on several factors such as the amount of $\mathrm{Cr}$, Mo and $\mathrm{N}$, the solution treatment temperature and for the most part on the cooling rate during quenching: higher the cooling rate, lower the number of precipitated phases $[12,13]$. From previous works, the critical cooling rate for 2205 has been established at $0.35^{\circ} \mathrm{C} / \mathrm{s}$ and for 2507 has been estimated as being higher than approximately $0.8-0.9^{\circ} \mathrm{C} / \mathrm{s}$, when a final $\sigma$-phase content of about $0.2 \%$ was obtained $[13,14]$. The precipitation kinetics of secondary phases becomes faster by finer ferrite and austenite grain size [8], due to the higher grain boundary surface, serving as preferential nucleation site [15].

In 2205 DSS and in Zeron100 SDSS $x$-phase is the first to precipitates after 3-5 min of isothermal aging, but the noses of precipitation curves lay at different temperatures: between $850{ }^{\circ} \mathrm{C}$ and $900{ }^{\circ} \mathrm{C}$ for 2205 and between $950{ }^{\circ} \mathrm{C}$ and $960^{\circ} \mathrm{C}$ for Zeron100. On the other hand, in 2101 and 2304 Lean DSSs, which are low-alloyed DSSs in comparison with the standard grades, such intermetallic phases have not been detected. The reduction of nickel and mainly of molybdenum contents seems to avoid precipitation of both $\chi$-phase and $\sigma$-phase, as only chromium nitrides have been observed [16].

Secondary phases are very detrimental both for mechanical properties (i.e., toughness, fracture strain) and for corrosion resistance. These phases cause a marked drop of absorbed impact energy even at very low intermetallic phases content $(0.5-1$ vol.\%) [17,18], also before $\sigma$-phase formation, when only a few small $\chi$-phase-particles were detected by metallographic techniques (SEM-BSE). On the contrary, low intermetallic contents scarcely affect material hardness. It is worthy to mention that recent investigations evidenced that the detrimental effect of secondary phase not only depends on their content, but also on their morphology [19].

The present paper reports the results obtained in a 2510 SDSS grade, which is usually employed as filler material in austenitic stainless steel welding. Generally, welded joint structural condition depends on the chemical composition of the weld metal, on the cooling rate after the welding process and on the post-weld heat treatment among others (i.e., heat-affected zone). DSSs are weldable by using the same procedures generally employed for high-alloyed steels [20] and, since their utilization is becoming increasingly widespread, a better understanding of metallurgical factors that influence their weldability is required. Few data are reported on the mechanisms of precipitation in the welding grade containing $25 \mathrm{wt} . \% \mathrm{Cr}, 10 \mathrm{wt} . \% \mathrm{Ni}$ and $4 \mathrm{wt} . \% \mathrm{Mo}$ and most of the studies concerning this steel are aimed to investigate its behavior as a filler material in the welds. However, for a better understanding of the basic physical metallurgy of intermetallic phase precipitation, it seems reasonable to study such solid-state transformations in simpler and more well-controlled conditions, i.e., under isothermal annealing. Subsequently, those studies will be helpful in modeling continuous cooling transformations typical of welded joints in order to avoid any secondary harmful phases during welding processes. 


\section{Materials and Methods}

The material under study was a commercial 2510 SDSS delivered as a $25 \mathrm{~mm}$ diameter milled and drawn bar in the solution annealed condition (annealed at $1100{ }^{\circ} \mathrm{C}$ and water quenched), whose chemical composition is reported in Table 1 and with PREN value of 43.

Table 1. Chemical composition of the investigated steel (wt.\%).

\begin{tabular}{ccccccccccc}
\hline Steel Grade & $\mathbf{C}$ & $\mathbf{S i}$ & $\mathbf{M n}$ & $\mathbf{C r}$ & $\mathbf{N i}$ & $\mathbf{M o}$ & $\mathbf{P}$ & $\mathbf{S}$ & $\mathbf{N}$ & $\mathbf{F e}$ \\
\hline 2510 SDSS & 0.020 & 0.44 & 0.37 & 25.30 & 9.9 & 4.0 & 0.018 & 0.001 & 0.275 & Bal. \\
\hline
\end{tabular}

The high content of $\mathrm{Cr}$ and Mo makes the steel very prone to ferrite retention, but the high amounts of $\mathrm{Ni}$ and $\mathrm{N}$ confirm that the composition of the material under study is balanced to counteract ferrite stabilization effect in the weld. In addition, nitrogen improves the corrosion resistance properties compared to ordinary duplex stainless steels, achieving the aforesaid PREN number.

Specimens for the isothermal treatments $(10 \mathrm{~mm} \times 10 \mathrm{~mm} \times 10 \mathrm{~mm})$ were obtained by cutting the bar in the transverse direction. The heat treatments were performed in the temperature range $850{ }^{\circ} \mathrm{C}-1080{ }^{\circ} \mathrm{C}$ for $3-30 \mathrm{~min}$ and for $24 \mathrm{~h}$, followed by water quenching (Table 2).

Table 2. Schematic of the heat treatments performed on the investigated material.

\begin{tabular}{cccccccccc}
\hline $\mathrm{T}\left({ }^{\circ} \mathrm{C}\right) / \mathrm{t}(\min )$ & 3 & 4 & 5 & 7 & 10 & 15 & 25 & 30 & $24 \mathrm{~h}$ \\
\hline 850 & & & & $\times$ & $\times$ & $\times$ & $\times$ & $\times$ & $\times$ \\
900 & $\times$ & $\times$ & $\times$ & & & & & $\times$ & $\times$ \\
950 & & & $\times$ & & & $\times$ & & & $\times$ \\
1000 & $\times$ & & $\times$ & & & & & & $\times$ \\
1050 & & & $\times$ & & $\times$ & & & & $\times$ \\
1080 & & & $\times$ & & $\times$ & & & & $\times$ \\
\hline
\end{tabular}

The volume percentage of ferrite and austenite in solution-treated samples were measured on 3 longitudinal and 3 transversal sections (20 fields for each section) with the aid of an image analysis software Leica Qwin (Leica Microsystems Imaging Solution Ltd., Cambridge, UK) on light micrographs at $200 \times$ magnification, after etching with Beraha's reagent ( $0.3 \mathrm{~g}$ potassium metabisulfite $\mathrm{K}_{2} \mathrm{~S}_{2} \mathrm{O}_{5}, 20 \mathrm{~mL}$ hydrochloric acid $\mathrm{HCl}, 80 \mathrm{~mL}$ distilled water, $10 \mathrm{~s}$ reaction time at room temperature). The microstructures of as-received and heat-treated samples were examined by means of a Scanning Electron Microscope (SEM) in backscattered mode (BSE), in order to observe the various phases on the basis of the difference in the average atomic number (Z-contrast) and to determine their chemical composition by microprobe analysis. The measurements were performed on a Leica Cambridge Stereoscan LEO 440 SEM (Leica Microsystems S.r.l., Milan, Italy), equipped with an energy-dispersive EDAX (EDAX, Mahwah, NJ, USA) detector (EDS). The measurements were performed at $29 \mathrm{kV}$, in order to maximize the Z-contrast on the BSE detector signal.

The thermodynamic calculation was employed to represent the equilibrium condition of the investigated steel. The modeling used in this work is based on the CALPHAD method (CALculation of PHAse Diagrams) [21] and the software Thermo-Calc (Thermo-Calc Software, Solna, Sweden) [22] was used in connection with the thermodynamic database TCFe6. The method is based on the minimization of Gibbs free energy of the phases provided by the Fe-C-Si-Mn-Cr-Ni-Mo-N multicomponent system.

\section{Results and Discussion}

\subsection{Thermodynamic Modeling}

The calculated diagram reported in Figure 1 represents the mole fraction of the phases as a function of the temperature. The solidification begins with the formation of primary ferrite $(\delta)$, whose existence 
is predicted down to $1000^{\circ} \mathrm{C}$. After passing $1370{ }^{\circ} \mathrm{C}$, the solid-state formation of austenite $(\gamma)$ from the primary ferrite begins and then, at about $1060^{\circ} \mathrm{C}$, ferrite gives rise to the simultaneous formation of austenite $(\gamma)$ and sigma ( $\sigma$-phase), through eutectoidic transformation. Below $980{ }^{\circ} \mathrm{C}$, the calculation provides the progressive transformation of austenite into $\sigma$-phase and chromium nitrides $\left(\mathrm{Cr}_{2} \mathrm{~N}\right)$ [23]. No $x$-phase precipitation is observed, in good agreement with [24].
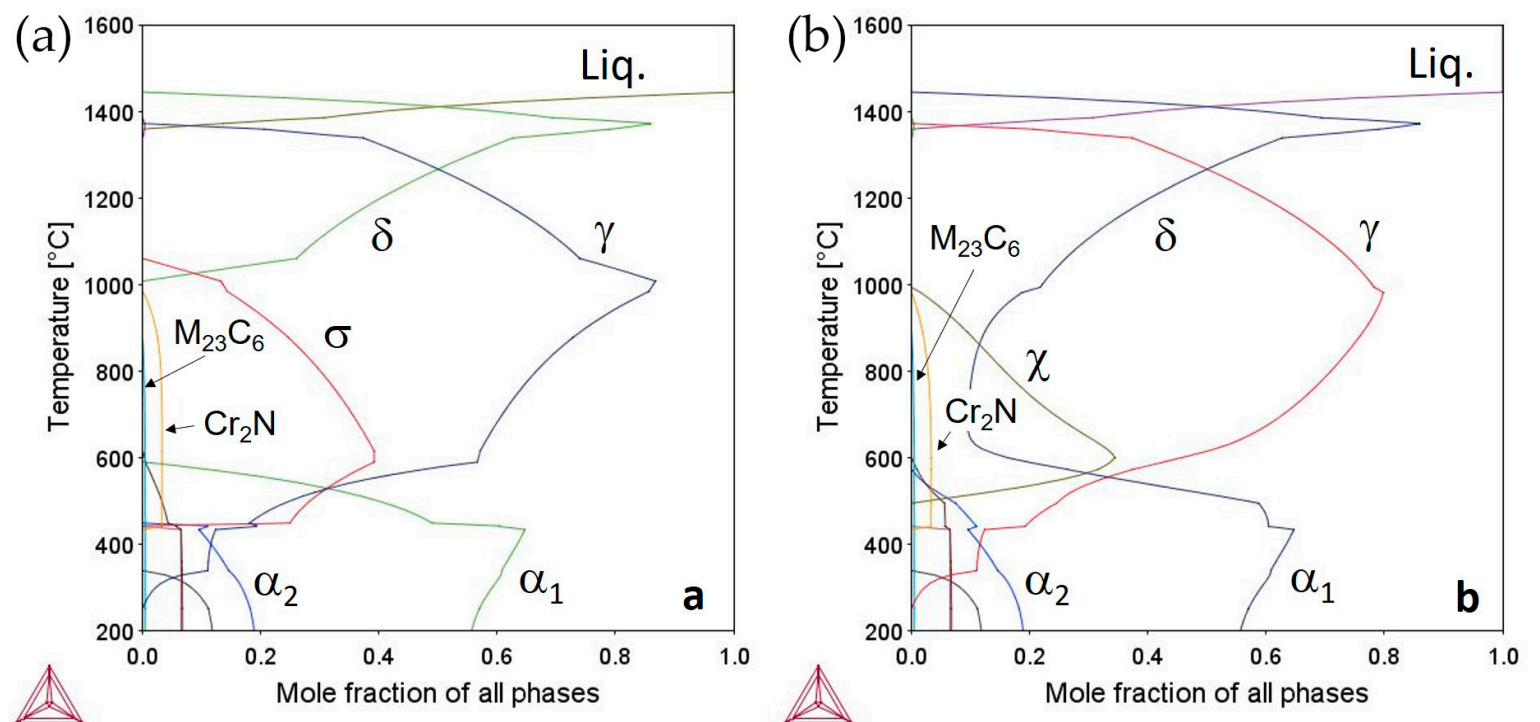

Figure 1. Diagrams showing the mole fraction of phases vs. temperature under equilibrium conditions

(a) and after suppressing $\sigma$-phase formation (b).

\subsection{As-Received Samples}

The base material (i.e., solution annealed at $1100{ }^{\circ} \mathrm{C}$ and water quenched) is free from secondary phases, in agreement with the results of thermodynamic modeling (Figure 1a). This evaluation confirms that $1100{ }^{\circ} \mathrm{C}$, as for the Zeron100 grade [24], is the correct solution annealing temperature for the 2510 SDSS under study, even if it may induce some grain coarsening.

The image analysis performed on the optical micrographs allowed to evaluate the volume percentage of both phases, which resulted in $30 \pm 1 \%$ of ferrite and $70 \pm 1 \%$ of austenite: the phase ratio is very close to that predicted by calculations at the solution annealing temperature $(29.4 \%$ ferrite, $70.6 \%$ austenite). These values are due to the high $\mathrm{Ni}$ and $\mathrm{N}$ contents, confirming that the chemical composition is well optimized to counteract a disproportionate ferrite increase in the weld. The compositions of the two phases and the partition coefficients of $\mathrm{Cr}$, Mo and Ni are reported in Table 3, where it is possible to notice that both ferrite and austenite have a well-balanced composition. Again, if the material is secondary phases free, Thermo-Calc calculated compositions are in good agreement with the experimental ones.

Table 3. (EDS) and calculated (Thermo-Calc) compositions of ferrite and austenite after solution treatment at $1100{ }^{\circ} \mathrm{C}$ and water quenching (wt.\%).

\begin{tabular}{ccccccc}
\hline \multirow{2}{*}{ Element } & \multicolumn{2}{c}{ Ferrite } & \multicolumn{2}{c}{ Austenite } & \multicolumn{2}{c}{$\begin{array}{c}\text { Partition Coefficient } \\
\text { (Ferrite/Austenite) }\end{array}$} \\
\cline { 2 - 7 } & EDS & Thermo-Calc & EDS & Thermo-Calc & EDS & Thermo-Calc \\
\hline Cr & 28.1 & 28.6 & 24.0 & 23.9 & 1.17 & 1.19 \\
Mo & 6.0 & 5.3 & 3.9 & 3.4 & 1.54 & 1.56 \\
Ni & 6.6 & 6.6 & 10.7 & 11.3 & 0.61 & 0.58 \\
\hline
\end{tabular}




\subsection{Heat-Treated Samples}

The heat treatment at $850{ }^{\circ} \mathrm{C}$ did not promote any phase transformation in the first $7 \mathrm{~min}$, while a considerable amount of $\sigma$-phase and $\chi$-phase was detected in the sample annealed for $10 \mathrm{~min}$ (Figure 2a). $\chi$-phase is visible as small and tiny bright particles which decorate ferrite grain boundaries, while coarser $\sigma$-phase precipitate at ferrite/austenite interface as well as inside ferritic grains and, as the holding time increases, it almost completely replaces the ferrite phase. The lamella morphology and the EDS analysis suggest that the phase transformation follows the eutectoid mechanism $\delta \rightarrow \sigma$-phase $+\gamma^{2}$ (secondary austenite).
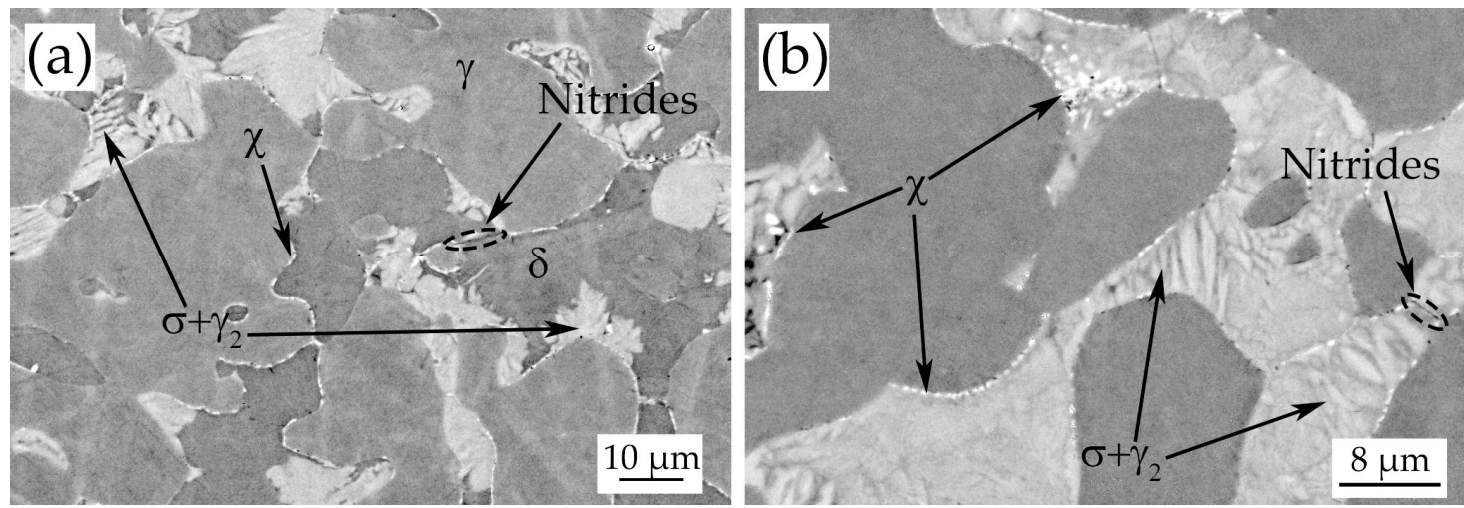

Figure 2. After heat treatment at $850^{\circ} \mathrm{C}$ for: $10 \mathrm{~min}(\mathbf{a})$ and $25 \mathrm{~min}(\mathbf{b})$.

The aging heat treatments at $850{ }^{\circ} \mathrm{C}$ for times longer than $10 \mathrm{~min}$ produced significant changes in the microstructure. It can be envisaged that ferrite transformation is almost complete after $30 \mathrm{~min}$, consistent with the equilibrium calculations shown in Figure 1a and Table 4.

Table 4. Volume percentage of various phases after $24 \mathrm{~h}$ heat treatment. TC refers to Thermo-Calc calculation, while Exp. to the experimentally measured percentage (vol.\%).

\begin{tabular}{ccccccccc}
\hline \multirow{2}{*}{ Temperature } & \multicolumn{2}{c}{ Ferrite } & \multicolumn{2}{c}{ Austenite } & \multicolumn{2}{c}{ Sigma } & \multicolumn{2}{c}{$\mathbf{C r}_{\mathbf{2}} \mathbf{N}$} \\
\cline { 2 - 9 } & TC & Exp. & TC & Exp. & TC & Exp. & TC & Exp. \\
\hline $\mathbf{8 5 0}{ }^{\circ} \mathbf{C}$ & - & - & 70.4 & 79.2 & 26.7 & 20.8 & 2.8 & yes \\
$\mathbf{9 0 0}{ }^{\circ} \mathbf{C}$ & - & - & 75.0 & 79.5 & 22.8 & 20.5 & 2.2 & yes \\
$\mathbf{9 5 0}{ }^{\circ} \mathbf{C}$ & - & - & 80.9 & 78.9 & 18.0 & 21.1 & 1.1 & - \\
$\mathbf{1 0 0 0}{ }^{\circ} \mathbf{C}$ & - & - & 86.4 & 79.9 & 13.6 & 20.1 & - & - \\
$\mathbf{1 0 5 0}{ }^{\circ} \mathbf{C}$ & 20.8 & 18.6 & 76.6 & 71.7 & 2.5 & 9.7 & - & - \\
$\mathbf{1 1 0 0}{ }^{\circ} \mathbf{C}$ & 30.0 & 29.4 & 70.0 & 70.6 & - & - & - & - \\
\hline
\end{tabular}

Figure 2 shows the microstructure of the samples treated at $850{ }^{\circ} \mathrm{C}$ for $25 \mathrm{~min}$ : as can be seen, ferrite mainly transformed into $\sigma$-phase and the amount of $\chi$-phase is lower than in the sample treated for $10 \mathrm{~min}$. Small dark particles at grain boundaries were identified as chromium nitrides.

The 30 min treatment caused the disappearance of $\chi$-phase and the total decomposition of ferrite, in agreement with similar results obtained for 2205 and the 2507 grades [25], isothermally heat-treated at $900{ }^{\circ} \mathrm{C}$ and $950{ }^{\circ} \mathrm{C}$ for times of 30-40 min. It seems that just such a short annealing time permits to approach equilibrium conditions. A very good agreement between thermodynamic calculations and experimental measurements (Figure 1a, Table 4) is confirmed. Indeed, at a low temperature, the calculation provides an overestimation of $\sigma$-phase content $(26.7 \%)$ compared to the experimental one $(20.8 \%)$. This can be explained considering that $\sigma$-phase preferably forms at ferrite/austenite interfaces, but its formation is delayed with increasing high coherent ferrite/austenite interfaces produced during quenching [26]. Present results confirm that $\chi$-phase is an intermediate, metastable transformation product, which is not predicted by equilibrium calculations. This thesis could be 
validated by suppressing the possible formation of $\sigma$-phase by Thermo-Calc, showing that $\chi$-phase becomes the next stable one (Figure $1 b$ ).

The presence of chromium nitrides is probably due to the high nitrogen content at grain boundaries accumulated during the quenching stage. In fact, diffusion of nitrogen from ferrite to austenite could be aided by the high interfaces dislocation density, which, therefore, could generate regions with a high nitrogen concentration and thus easing the $\mathrm{Cr}_{2} \mathrm{~N}$ precipitation during the subsequent isothermal holding. The most evident nitrides precipitation in the present grade in comparison with 2205 [13,24,25] could be explained by the higher nitrogen amount $(0.275 \%$ versus $0.16 \%)$.

At $900{ }^{\circ} \mathrm{C}$, precipitation starts after $5 \mathrm{~min}$ and is very abundant, with $\chi$-phase preferentially distributed at grain boundaries and $\sigma$-phase inside ferritic grains (Figure 3a).
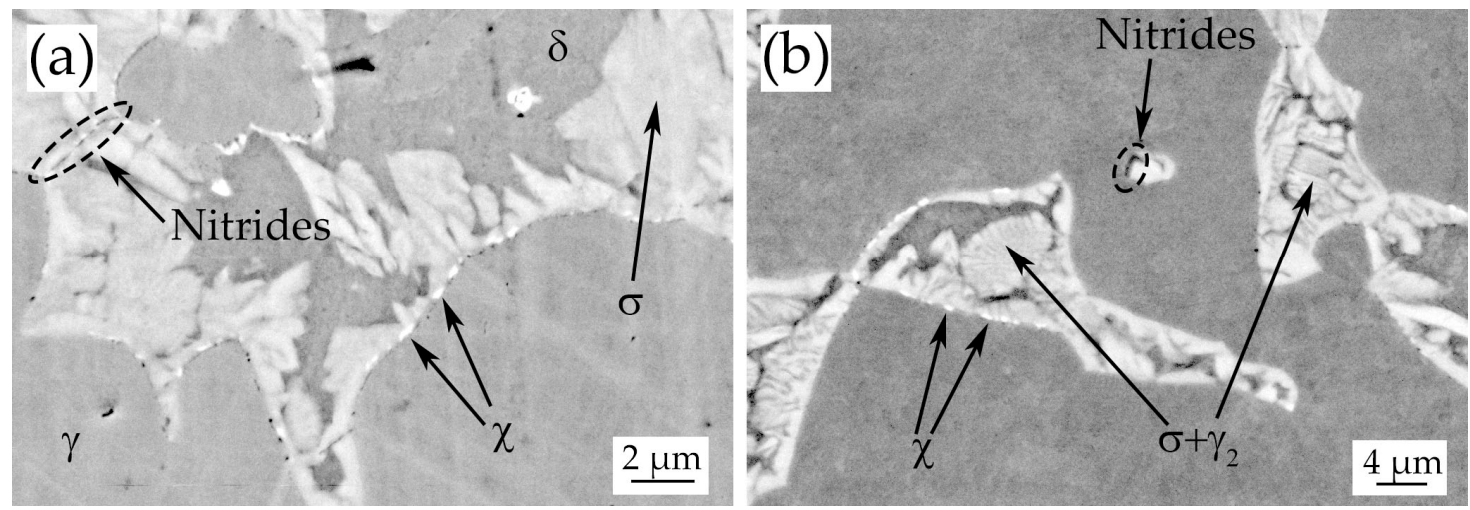

Figure 3. Microstructure after heat treatment at $900{ }^{\circ} \mathrm{C} 5 \mathrm{~min}(\mathbf{a}), 950{ }^{\circ} \mathrm{C} 15 \mathrm{~min}(\mathbf{b})$.

The amount of $\chi$-phase decreases for times longer than $5 \mathrm{~min}$, and ferrite is totally transformed into $\sigma$-phase after $30 \mathrm{~min}$.

The volumetric percentage of ferrite after $24 \mathrm{~h}$ annealing, measured by image analysis is $20.5 \%$, in good agreement with that provided by Thermo-Calc calculations $(22.8 \%)$ after $24 \mathrm{~h}$ annealing (Table 4).

Most probably, the higher annealing temperature allows the coherent-incoherent transition of ferrite/austenite interface, allowing faster kinetics for the eutectoidic transformation. Small Cr nitrides are detected at grain boundaries.

At $950{ }^{\circ} \mathrm{C}$, eutectoidic decomposition of ferrite is completed after $15 \mathrm{~min}, \chi$-phase particles are less frequent than at $850^{\circ} \mathrm{C}$ and $900{ }^{\circ} \mathrm{C}$, and small $\mathrm{Cr}$ nitrides are present. As it was outlined for the lower temperature values, increasing aging time, $\sigma$-phase gets coarser, growing from the boundaries inside the ferritic grains. In the literature, it is reported as a progressive transformation of $\chi$-phase into $\sigma$-phase (Figure 3b). However, a different further explanation is possible. The trend of $\chi$-phase precipitation is similar to the ones evidenced in 2205 and 2507, where $\chi$-phase was the first phase to precipitate but its amount decreases as the holding time increases. This behavior could be justified considering that the lower coherency strains with the ferrite lattice [27] favors $\chi$-phase over $\sigma$-phase nucleation. As a matter of fact, $\chi$-phase has a cubic lattice and a well-defined orientation relationship with the host lattice [27]. This kinetic effect could become important at intermediate cooling rates, favoring the increase and the peak of $\chi$-phase -phase amount. The decreasing cooling rates can be assimilated to long holding time in isothermal treatment, as the time for precipitation increases and, therefore, this kinetic effect becomes less important. Consequently, $\sigma$-phase formation prevails, in agreement with equilibrium data, as already observed in other DSSs. At $1000^{\circ} \mathrm{C}$, precipitation starts after $3 \mathrm{~min}$, but only $\sigma$-phase has been detected. This is in good agreement with the metastable thermodynamic equilibrium (Figure 1b) showing that this temperature represents the highest precipitation temperature for $\chi$-phase. Considering that significant precipitation kinetics will be only appreciated at a given undercooling, it is explained why no precipitation of this phase is observed. The amount of $\sigma$-phase 
increases with holding time, and ferrite islands are gradually embedded (Figure 4a), similar behavior has been evidenced in 2507 [25].
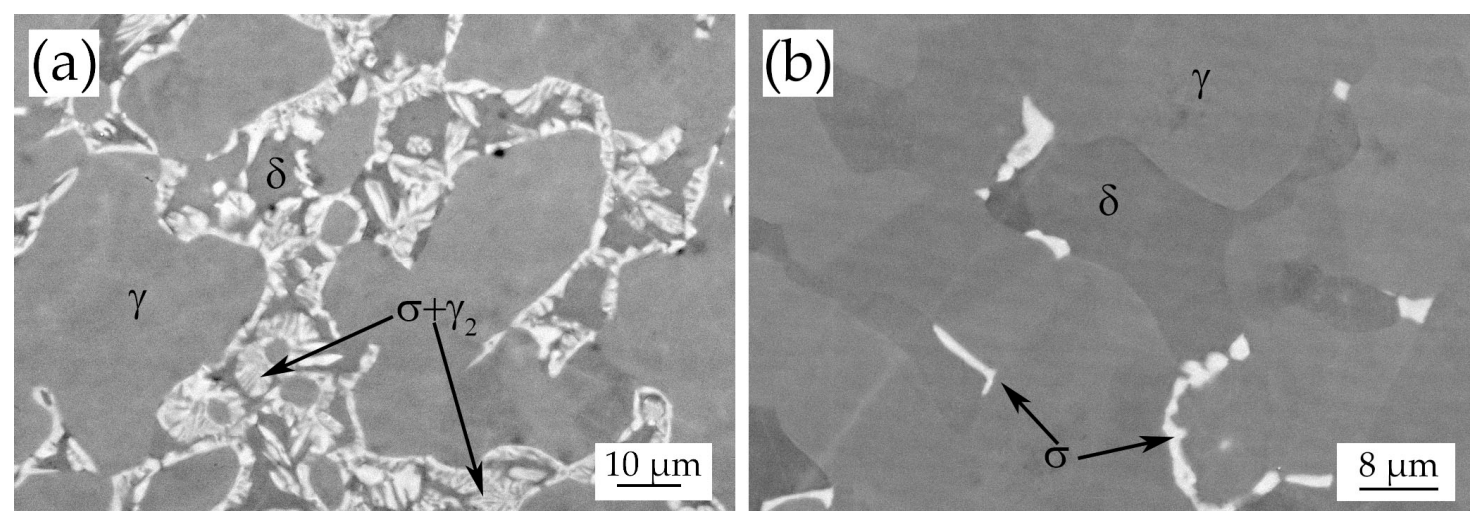

Figure 4. Microstructure after heat treatment at $1000^{\circ} \mathrm{C} 3 \mathrm{~min}(\mathbf{a}), 1080^{\circ} \mathrm{C} 10 \mathrm{~min}(\mathbf{b})$.

At 1000 and $1080^{\circ} \mathrm{C}$, precipitation starts for longer times than in the previous cases, with a lower amount of $\sigma$-phase after $3 \mathrm{~min}$ in comparison with lower temperature treatment and the absence of $\chi$-phase and nitrides (Figure 4a). As the aging time increases, the amount of secondary phases increases very slowly thanks to the diffusion of $\mathrm{Cr}$ and Mo from $\sigma$-phase to ferrite solid solution, according to the progressive dissolution of $\sigma$-phase as in the solution annealing treatment. In particular, the microstructure of the sample treated at $1080^{\circ} \mathrm{C}$ for $10 \mathrm{~min}$ consists of austenite, ferrite and about 2 vol.\% of $\sigma$-phase (Figure $4 \mathrm{~b}$ ). It is worth considering that Thermo-Calc computations do not predict any $\sigma$-phase above $1056^{\circ} \mathrm{C}$, indicating a possible underestimation of the precipitation temperature by the phase computation software.

The treatments for $24 \mathrm{~h}$ at $850-1000^{\circ} \mathrm{C}$ (Figure 5) result in a complete ferrite decomposition, in a very high amount of nitrides at $900{ }^{\circ} \mathrm{C}$ and austenite grain growth at $950-1000{ }^{\circ} \mathrm{C}$. The sample treated for $24 \mathrm{~h}$ at $1050{ }^{\circ} \mathrm{C}$ consists of austenite, ferrite and approximately $10 \%$ of $\sigma$-phase. This confirms the progressive dissolution of $\sigma$-phase and suggests that 2510 has to be solubilized at temperatures higher than $1050{ }^{\circ} \mathrm{C}$, as expected due to the higher $\mathrm{Cr}$ and Mo contents compared to other DSS grades. It is also interesting to note the different $\sigma$-phase morphology at higher temperatures (Figure 5e) changing from typical eutectoidic morphology into blocky precipitates. This is due to the influence of nucleation force which dominates at lower temperatures, while the diffusion effect is dominating at higher temperatures [28]. 

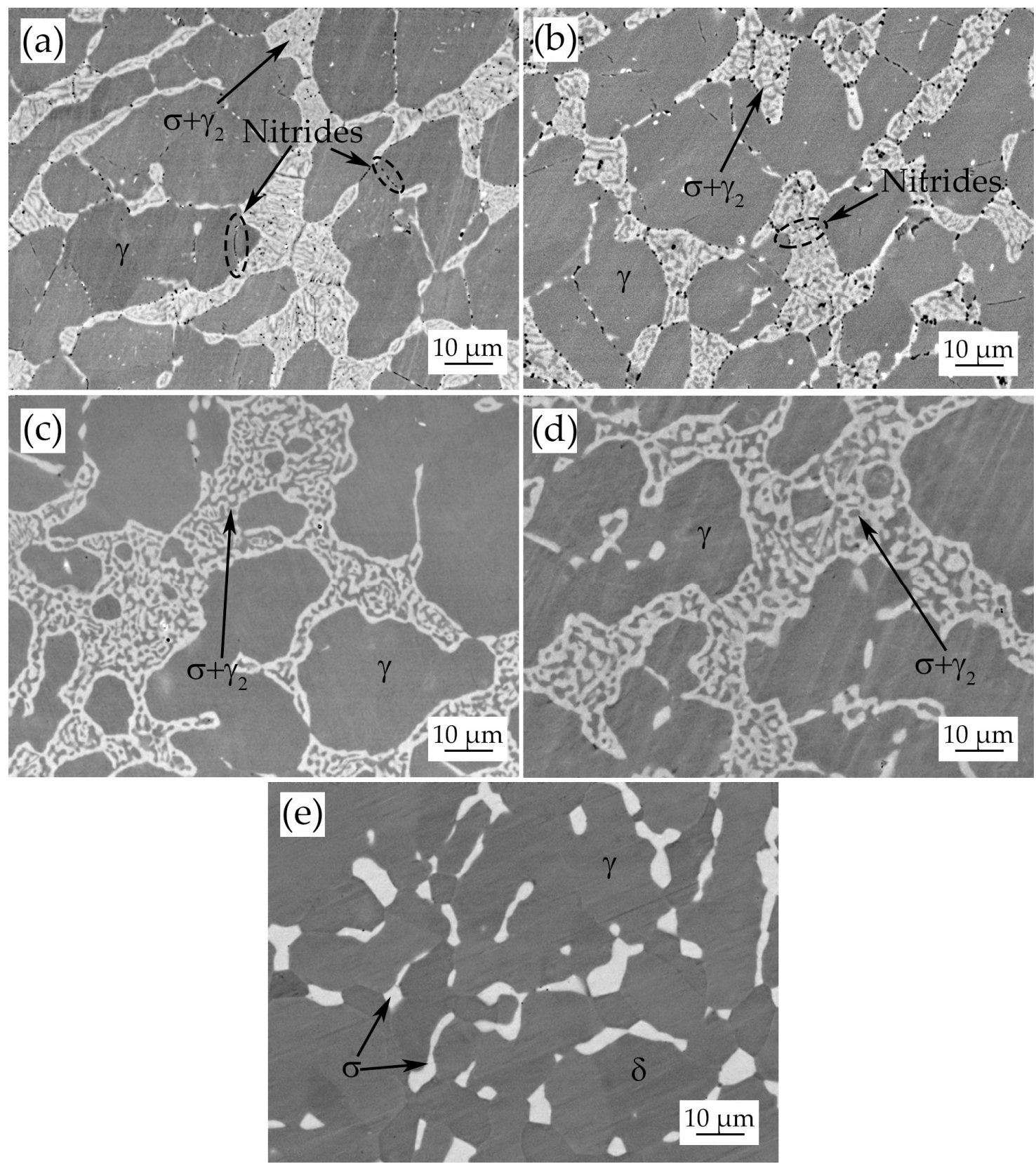

Figure 5. Microstructure after $24 \mathrm{~h}$ heat treatment at: $850{ }^{\circ} \mathrm{C}(\mathbf{a}), 900{ }^{\circ} \mathrm{C}(\mathbf{b}), 950{ }^{\circ} \mathrm{C}(\mathbf{c}), 1000{ }^{\circ} \mathrm{C}(\mathbf{d})$ and $1050{ }^{\circ} \mathrm{C}(\mathbf{e})$.

\subsection{Chemical Composition of the Phases}

Some further observations can be made regarding the reliability of the chemical compositions predicted by the thermodynamic calculations. For the purpose of validation, phase fractions, and concentrations of elements in such phases obtained by EDS at the longest holding times $(24 \mathrm{~h})$ are considered. Data in Table 5 show that the chemical compositions of most phases are only slightly affected by the annealing time in the first $30 \mathrm{~min}$, while a remarkable change is observed after $24 \mathrm{~h}$. 
Table 5. EDS phases chemical composition at different temperatures and soaking times and Thermo-Calc calculated composition (bold between brackets).

\begin{tabular}{|c|c|c|c|c|c|c|c|c|c|c|}
\hline \multirow{2}{*}{ Temperature } & \multirow{2}{*}{ Time } & \multicolumn{3}{|c|}{ Ferrite } & \multicolumn{3}{|c|}{ Austenite } & \multicolumn{3}{|c|}{ Sigma } \\
\hline & & $\mathrm{Cr}$ & $\mathrm{Ni}$ & Mo & $\mathrm{Cr}$ & $\mathrm{Ni}$ & Mo & $\mathrm{Cr}$ & $\mathrm{Ni}$ & Mo \\
\hline \multirow[b]{2}{*}{$850^{\circ} \mathrm{C}$} & $30^{\prime}$ & - & - & - & 23.8 & 11.0 & 3.8 & 28.3 & 6.4 & 6.5 \\
\hline & $24 \mathrm{~h}$ & - & - & - & $\begin{array}{c}24.3 \\
(19.7)\end{array}$ & $\begin{array}{c}11.1 \\
(12.4)\end{array}$ & $\begin{array}{c}3.7 \\
(1.7)\end{array}$ & $\begin{array}{c}30.1 \\
(35.4)\end{array}$ & $\begin{array}{c}5.6 \\
(4.3)\end{array}$ & $\begin{array}{c}8.2 \\
(9.8)\end{array}$ \\
\hline \multirow[b]{2}{*}{$900^{\circ} \mathrm{C}$} & $30^{\prime}$ & - & - & - & 23.9 & 11.0 & 3.5 & 28.3 & 6.6 & 6.5 \\
\hline & $24 \mathrm{~h}$ & - & - & - & $\begin{array}{c}24.2 \\
(21.1)\end{array}$ & $\begin{array}{c}11.0 \\
(11.8)\end{array}$ & $\begin{array}{c}3.7 \\
(1.9)\end{array}$ & $\begin{array}{c}30.3 \\
(34.9)\end{array}$ & $\begin{array}{c}5.9 \\
(4.4)\end{array}$ & $\begin{array}{c}9.0 \\
(10.5)\end{array}$ \\
\hline \multirow[b]{2}{*}{$950{ }^{\circ} \mathrm{C}$} & $5^{\prime}$ & - & - & - & 23.7 & 10.9 & 3.9 & 28.2 & 7.1 & 7.4 \\
\hline & $24 \mathrm{~h}$ & - & - & - & $\begin{array}{c}23.9 \\
(22.6)\end{array}$ & $\begin{array}{c}11.1 \\
(11.2)\end{array}$ & $\begin{array}{c}3.8 \\
(2.3)\end{array}$ & $\begin{array}{c}28.9 \\
(34.3)\end{array}$ & $\begin{array}{c}5.9 \\
(4.5) \\
\end{array}$ & $\begin{array}{c}10.5 \\
(11.4) \\
\end{array}$ \\
\hline \multirow[b]{2}{*}{$1000^{\circ} \mathrm{C}$} & $5^{\prime}$ & - & - & - & 23.7 & 11.2 & 3.7 & 28.00 & 6.9 & 7.5 \\
\hline & $24 \mathrm{~h}$ & - & - & - & $\begin{array}{c}24.1 \\
(23.9)\end{array}$ & $\begin{array}{c}11.3 \\
(10.8)\end{array}$ & $\begin{array}{c}3.5 \\
(2.6)\end{array}$ & $\begin{array}{c}31.3 \\
(33.7)\end{array}$ & $\begin{array}{c}5.5 \\
(4.6)\end{array}$ & $\begin{array}{c}10.1 \\
(12.2)\end{array}$ \\
\hline \multirow[b]{2}{*}{$1050^{\circ} \mathrm{C}$} & $10^{\prime}$ & 28.4 & 6.3 & 5.7 & 24.2 & 11.4 & 3.8 & 30.1 & 5.7 & 11.0 \\
\hline & $24 \mathrm{~h}$ & $\begin{array}{c}28.9 \\
(29.4)\end{array}$ & $\begin{array}{c}6.1 \\
(6.1)\end{array}$ & $\begin{array}{c}5.9 \\
(5.2)\end{array}$ & $\begin{array}{c}23.7 \\
(23.9)\end{array}$ & $\begin{array}{c}10.9 \\
(11.1)\end{array}$ & $\begin{array}{c}3.4 \\
(3.3)\end{array}$ & $\begin{array}{c}31.1 \\
(32.3)\end{array}$ & $\begin{array}{c}5.4 \\
(4.8)\end{array}$ & $\begin{array}{c}11.8 \\
(14.1)\end{array}$ \\
\hline
\end{tabular}

According to previous works, it is plausible that equilibrium conditions can be achieved after $24 \mathrm{~h} \mathrm{[29].}$

Above $1000{ }^{\circ} \mathrm{C}$ Thermo-Calc accurately predicts percentage fractions of austenite and ferrite (Table 4), i.e., the two only phases present after solution annealing [23]. At lower temperature, in particular, below the secondary phase precipitation temperature $\left(1056{ }^{\circ} \mathrm{C}\right.$ for $\sigma$-phase, $1000{ }^{\circ} \mathrm{C}$ for $\chi$-phase) the result of calculations diverges from the experimental ones. In particular, between $900{ }^{\circ} \mathrm{C}$ and $1056^{\circ} \mathrm{C} \sigma$-phase volume fraction is overestimated, consequently, austenite percentage (\%austenite $=100 \%-\% \sigma$-phase $)$ is underestimated. The opposite occurs at temperatures below $900{ }^{\circ} \mathrm{C}$, in agreement with [23], and a possible reason was already reported above. The evidence that TCFe6 fails to estimate the correct phases volume fraction involves a predictable error also in the composition of the phases. According to [24], austenite composition would be more accurate for $\mathrm{Ni}$ and $\mathrm{Mo}$ and less accurate for $\mathrm{Cr}$ content. On the contrary, in our case, we demonstrate an almost extraordinary congruence at $1050^{\circ} \mathrm{C}$. Cr and Mo are underestimated by Thermo-Calc at the lower temperature, while the $\mathrm{Ni}$ amount shows excellent correspondence at all temperatures.

Tables 5 and 6 show that the calculated chemical compositions are generally overestimated in $\mathrm{Cr}$ and Mo content in $\sigma$-phase and underestimated in austenite. Ni content, on the other hand, is underestimated in $\sigma$-phase.

Table 6. Nitrides composition calculated with Thermo-Calc.

\begin{tabular}{ccccccccc}
\hline Temperature & Si & Mn & $\mathbf{C r}$ & $\mathbf{N i}$ & Mo & $\mathbf{C}$ & $\mathbf{N}$ & Fe \\
\hline $\mathbf{8 5 0}{ }^{\circ} \mathbf{C}$ & 0 & 0.06 & 81.73 & 0.08 & 5.95 & 0.37 & 10.51 & Balance \\
$\mathbf{9 0 0}{ }^{\circ} \mathbf{C}$ & 0 & 0.06 & 82.06 & 0.11 & 5.11 & 0.40 & 10.40 & Balance \\
$\mathbf{9 5 0}{ }^{\circ} \mathbf{C}$ & 0 & 0.06 & 82.20 & 0.14 & 4.43 & 0.34 & 10.40 & Balance \\
$\mathbf{1 0 0 0}{ }^{\circ} \mathbf{C}$ & - & - & - & - & - & - & - & Balance \\
$\mathbf{1 0 5 0}{ }^{\circ} \mathbf{C}$ & - & - & - & - & - & - & - & Balance \\
$\mathbf{1 1 0 0}{ }^{\circ} \mathbf{C}$ & - & - & - & - & - & - & - & Balance \\
\hline
\end{tabular}

Different hypotheses can be put forward to explain this evidence. The first one is that the eutectoidic transformation occurs with limited partitioning of elements between austenite and $\sigma$-phase. Elmer 
et al. showed by in situ synchrotron X-ray diffraction that $\sigma$-phase formation mechanisms between $700{ }^{\circ} \mathrm{C}$ and $850^{\circ} \mathrm{C}$ changed from discontinuous precipitation in the early stages of transformation to the growth of the existing $\sigma$-phase after nucleation site saturation [30]. This last mechanism reduces elements diffusion and partitioning between the product phases.

The second one is that the annealing time could be still too short to achieve full thermodynamic equilibrium, but this seems to be excluded by a previous kinetic study [29].

The third hypothesis is that the TCFe6 database could be not sufficiently reliable, yet.

Compositions of $\chi$-phase and $\sigma$-phases are not affected by the composition of the as-received material; their values are in good agreement with those mentioned in the literature for different steels [31,32]. As expected, $\chi$-phase appears more enriched in Mo and $\mathrm{Cr}[33,34]$ than $\sigma$-phase, even if its size is below the spot beam size (about $0.5-1 \mu \mathrm{m}$ ), resulting in an obvious underestimation of $\mathrm{Cr}$ and Mo contents in $\sigma$-phase due to the lower amount of such elements in the surrounding matrix [35].

\subsection{Precipitation Kinetics}

Time-Temperature-Precipitation (TTP) curves for $\sigma$-phase and $\chi$-phase precipitation are reported in Figure 6: the noses of the curves are respectively at $1000{ }^{\circ} \mathrm{C}(2.5 \mathrm{~min})$ and $925^{\circ} \mathrm{C}(4 \mathrm{~min})$. These values are shifted toward a slightly higher temperature than in the Zeron 100 grade while the times are inverted. In Zeron100, $\chi$-phase precipitates for a shorter time than $\sigma$-phase in all the temperature range, while in 2510 this trend is observed only for temperatures lower than $900{ }^{\circ} \mathrm{C}$, with $\sigma$-phase as the first precipitating phase starting from temperatures higher than $900{ }^{\circ} \mathrm{C}$.

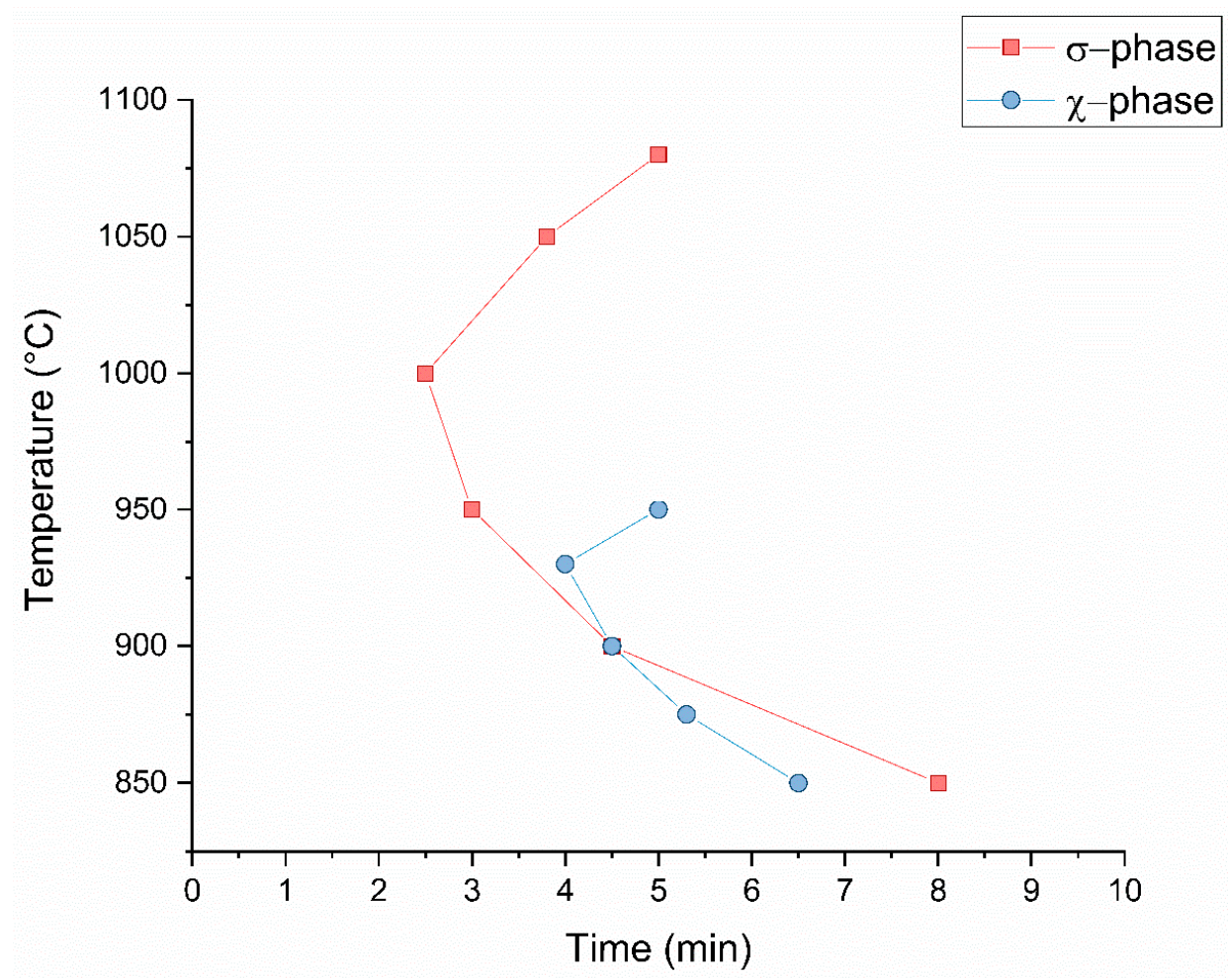

Figure 6. The first observed appearance of $\sigma$-phase and $\chi$-phase (approximately $0.1 \%$ ).

\section{Conclusions}

In the present work, the solid-state phase transformations occurring in 2510 DSS during isothermal aging are discussed, and the results can be summarized as follows:

- During the isothermal treatments at $850{ }^{\circ} \mathrm{C}-1080{ }^{\circ} \mathrm{C} \sigma$-phase and $\chi$-phase precipitate at the $\delta / \gamma$ grain boundaries after $4-10 \mathrm{~min}$. 
- The noses of TTP curves for $\sigma$-phase and $\chi$-phase are at $1000{ }^{\circ} \mathrm{C}(2.5 \mathrm{~min})$ and at $925^{\circ} \mathrm{C}(4 \mathrm{~min})$, respectively. These points are at a higher temperature, if compared to those of 2205 and 2507 grades, and the precipitation is more copious: these can be ascribed to the higher $\mathrm{Cr}$ and Mo content, which favors ferrite transformation.

- Ferrite completely transforms after a relatively short holding time (5-30 $\mathrm{min}$ ) at every temperature.

- Chromium nitrides (probably $\mathrm{Cr}_{2} \mathrm{~N}$ ) were detected at grain boundaries in every treated sample up to $900^{\circ} \mathrm{C}$.

- Experimental results are in good agreement with those predicted by thermodynamic modeling provided by Thermo-Calc software and TCFe6 database: the temperature range of phase stability is predicted with reasonable accuracy, as well as the volume fraction and phase composition. Most discrepancies were ascribed to kinetic effects, i.e., the slowdown of eutectic decomposition leading to $\sigma$-phase formation and the reduced elements partitioning below $900{ }^{\circ} \mathrm{C}$.

- The present study is a starting point to understand and model continuous cooling transformations of the welding process to improve welding quality in terms of mechanical, metallurgical and corrosion properties.

Author Contributions: Conceptualization, I.C., M.B. and M.P.; methodology, M.B., C.G., L.P.; software, M.P.; validation, M.P., A.Z. and I.C.; formal analysis, M.B., L.P. and C.G.; investigation, M.B.; resources, I.C.; data curation, M.B., C.G., L.P.; writing — original draft preparation, M.B., I.C. and M.P.; writing-review and editing, C.G., L.P., I.C., M.P. and A.Z.; visualization, C.G. and M.B.; supervision, I.C., A.Z. and M.P.; project administration, I.C.; funding acquisition, I.C. All authors have read and agreed to the published version of the manuscript.

Funding: This research was funded by PuCEAF project, Progetti SID 2019 (CALL_SID19_01), Università degli Studi di Padova.

Conflicts of Interest: The authors declare no conflicts of interest.

\section{References}

1. Nilsson, J.-O. Super duplex stainless steels. Mater. Sci. Technol. 1992, 8, 685-700. [CrossRef]

2. Nilsson, J.O.; Kangas, P.; Karlsson, T.; Wilson, A. Microstructural stability and mechanical properties of a high nitrogen super duplex stainless steel. Mater. Sci. Forum 1999, 318, 751-756. [CrossRef]

3. Chen, T.H.; Weng, K.L.; Yang, J.R. The effect of high-temperature exposure on the microstructural stability and toughness property in a 2205 duplex stainless steel. Mater. Sci. Eng. A 2002, 338, 259-270. [CrossRef]

4. Karlsson, L.; Bengtsson, L.; Rolander, U.; Pak, S. The Kinetics of Intermetallic Phase Formation and is Effect on Corrosion Resistance of Duplex Stainless Steels SS 2377 (UNS 31803). In Application of Stainless Steels; The Institute of Metaks: Stockholm, Sweden, 1992; p. 335.

5. Kashiwar, A.; Vennela, N.P.; Kamath, S.L.; Khatirkar, R.K. Effect of solution annealing temperature on precipitation in 2205 duplex stainless steel. Mater. Charact. 2012, 74, 55-63. [CrossRef]

6. Leiva-García, R.; Fernandes, J.C.S.; Muñoz-Portero, M.J.; García-Antón, J. Study of the sensitisation process of a duplex stainless steel (UNS 1.4462) by means of confocal microscopy and localised electrochemical techniques. Corros. Sci. 2015, 94, 327-341. [CrossRef]

7. Guo, Y.; Sun, T.; Hu, J.; Jiang, Y.; Jiang, L.; Li, J. Microstructure evolution and pitting corrosion resistance of the Gleeble-simulated heat-affected zone of a newly developed lean duplex stainless steel 2002. J. Alloys Compd. 2016, 658, 1031-1040. [CrossRef]

8. Melo, E.A.; Magnabosco, R. Influence of the Heterogeneous Nucleation Sites on the Kinetics of Intermetallic Phase Formation in Aged Duplex Stainless Steel. Metall. Mater. Trans. A Phys. Metall. Mater. Sci. 2017, 48, 5273-5284. [CrossRef]

9. Yang, S.M.; Chen, Y.C.; Chen, C.H.; Huang, W.P.; Lin, D.Y. Microstructural characterization of $\delta / \gamma / \sigma / \gamma 2 / \chi$ phases in silver-doped 2205 duplex stainless steel under $800{ }^{\circ} \mathrm{C}$ aging. J. Alloys Compd. 2015, 633, 48-53. [CrossRef]

10. Llorca-Isern, N.; López-Luque, H.; López-Jiménez, I.; Biezma, M.V. Identification of sigma and chi phases in duplex stainless steels. Mater. Charact. 2016, 112, 20-29. [CrossRef]

11. Breda, M.; Pellizzari, M.; Frigo, M. $\sigma$-Phase in lean duplex stainless steel sheets. Acta Metall. Sin. (Engl. Lett.) 2015, 28, 331-337. [CrossRef] 
12. Johnson, E.; Kim, Y.J.; Scott Chumbley, L.; Gleeson, B. Initial phase transformation diagram determination for the CD3MN cast duplex stainless steel. Scr. Mater. 2004, 50, 1351-1354. [CrossRef]

13. Calliari, I.; Zanesco, M.; Ramous, E. Influence of isothermal aging on secondary phases precipitation and toughness of a duplex stainless steel SAF 2205. J. Mater. Sci. 2006, 41, 7643-7649. [CrossRef]

14. Domínguez-Aguilar, M.A.; Newman, R.C. Detection of deleterious phases in duplex stainless steel by weak galvanostatic polarization in alkaline solution. Corros. Sci. 2006, 48, 2560-2576. [CrossRef]

15. da Fonseca, G.S.; Mendes, P.S.N.; Silva, A.C.M. Sigma Phase: Nucleation and Growth. Metals 2019, 9, 34. [CrossRef]

16. Straffelini, G.; Baldo, S.; Calliari, I.; Ramous, E. Effect of Aging on the Fracture Behavior of Lean Duplex Stainless Steels. Metall. Mater. Trans. A 2009, 40, 2616-2621. [CrossRef]

17. Calliari, I.; Ramous, E.; Bassani, P. Phase Transformation in Duplex Stainless Steels after Isothermal Treatments, Continuous Cooling and Cold Working. Mater. Sci. Forum 2010, 638-642, 2986-2991. [CrossRef]

18. Calliari, I.; Breda, M.; Ramous, E.; Brunelli, K.; Pizzo, M.; Menapace, C. Impact toughness of an isothermally treated Zeron®100 SDSS. J. Mater. Eng. Perform. 2012, 21, 2117-2123. [CrossRef]

19. Hosseini, V.A.; Karlsson, L.; Wessman, S.; Fuertes, N. Effect of sigma phase morphology on the degradation of properties in a super duplex stainless steel. Materials 2018, 1, 933. [CrossRef]

20. Kaçar, R.; Baylan, O. An investigation of microstructure/property relationships in dissimilar welds between martensitic and austenitic stainless steels. Mater. Des. 2004, 25, 317-329. [CrossRef]

21. Mallik, A.K. Computer calculations of phase diagrams. Bull. Mater. Sci. 1986, 8, 107-121. [CrossRef]

22. Sundman, B.; Jansson, B.; Andersson, J.O. The Thermo-Calc databank system. Calphad 1985, 9, $153-190$. [CrossRef]

23. Wessman, S.; Pettersson, R.; Hertzman, S. On phase equilibria in duplex stainless steels. Steel Res. Int. 2010, 81, 337-346. [CrossRef]

24. Calliari, I.; Pellizzari, M.; Ramous, E. Precipitation of secondary phases in super duplex stainless steel ZERON100 isothermally aged. Mater. Sci. Technol. 2011, 27, 928-932. [CrossRef]

25. Calliari, I.; Pellizzari, M.; Zanellato, M.; Ramous, E. The phase stability in Cr-Ni and Cr-Mn duplex stainless steels. J. Mater. Sci. 2011, 46, 6916-6924. [CrossRef]

26. Sato, Y.S.; Kokawa, H. Preferential precipitation site of sigma phase in duplex stainless steel weld metal. Scr. Mater. 1999, 40, 659-663. [CrossRef]

27. Kasper, J.S. The ordering of atoms in the chi-phase of the iron-chromium-molybdenum system. Acta Metall. 1954, 2, 456-461. [CrossRef]

28. Pohl, M.; Storz, O.; Glogowski, T. $\sigma$-phase morphologies and their effect on mechanical properties of duplex stainless steels. Int. J. Mater. Res. 2008, 99, 1163-1170. [CrossRef]

29. Magnabosco, R. Kinetics of sigma phase formation in a duplex stainless steel. Mater. Res. 2009, 12, $321-327$. [CrossRef]

30. Elmer, J.; Palmer, T.; Specht, E. Direct Observations of Sigma Phase Formation in Duplex Stainless Steels using In Situ Synchrotron X-Ray Diffraction. Metall. Trans. A 2007, 38, 464-475. [CrossRef]

31. Byun, S.H.; Kang, N.; Lee, T.H.; Ahn, S.K.; Lee, H.W.; Chang, W.S.; Cho, K.M. Kinetics of Cr/Mo-rich precipitates formation for 25Cr-6.9Ni-3.8Mo-0.3N super duplex stainless steel. Met. Mater. Int. 2012, 18, 201-207. [CrossRef]

32. Kim, Y.J.; Ugurlu, O.; Jiang, C.; Gleeson, B.; Chumbley, L.S. Microstructural evolution of secondary phases in the cast duplex stainless steels CD3MN and CD3MWCuN. Metall. Mater. Trans. A Phys. Metall. Mater. Sci. 2007, 38, 203-211. [CrossRef]

33. Calliari, I.; Brunelli, K.; Dabalà, M.; Ramous, E. Measuring secondary phases in duplex stainless steels. J. Miner. Met. Mater. Soc. 2009, 61, 80-83. [CrossRef]

34. Deng, B.; Jiang, Y.M.; Gao, J.; Li, J. Effect of annealing treatment on microstructure evolution and the associated corrosion behavior of a super-duplex stainless steel. J. Alloys Compd. 2010, 493, 461-464. [CrossRef]

35. Calliari, I.; Dabalà, M.; Ramous, E.; Straffelini, G. New Lean Duplex Stainless Steels for Structural Applications. Mater. Sci. Forum 2008, 604-605, 419-426. [CrossRef]

(C) 2020 by the authors. Licensee MDPI, Basel, Switzerland. This article is an open access article distributed under the terms and conditions of the Creative Commons Attribution (CC BY) license (http://creativecommons.org/licenses/by/4.0/). 